\title{
Response to editorial: Diagnosing carotid near-occlusion with 1-mm side-to-side asymmetry: a tough task made too easy
}

\author{
Suvi Maaria Koskinen ${ }^{1,2} \cdot$ Leena Valanne ${ }^{2}$ - Lauri Soinne ${ }^{3}$
}

Received: 5 May 2017 / Accepted: 8 May 2017 /Published online: 16 May 2017

(C) Springer-Verlag Berlin Heidelberg 2017

We heartily thank colleagues Johansson and Fox for their keen interest and profound insight into the perils of diagnosing carotid near-occlusion they show in their editorial response to our paper "Recognizing subtle near-occlusion in carotid stenosis patients: a computed tomography angiographic study" $[1,2]$. They go out of their way to review the interpretative approach to near-occlusion, and they do it with great clarity. As it stands, the optimized analysis is a complex synthesis of the findings, taking into account the limitations of the technical methodology as well; still, the dialectics of the process might benefit from simpler tools, as well.

On the pragmatic diagnostic side, it is probably of importance that the possibility of a near-occlusion is being considered. As Johansson and Fox point out, we have firstly wanted to raise this awareness. Secondly, straightforward yardsticks for screening may be useful, especially for the less experienced. Fully aware of the perils of diagnosis and of not ending up with any once-for-all solution, we set out to experiment with a simple and easy-to-use cutoff, and it turned out to have a good concordance with the visual assessment of the presence of near-occlusion. Consequently, rather than be doomed before the trial, we feel that this simplified criterion may be

Suvi Maaria Koskinen

suvi.koskinen@helsinki.fi

1 Clinicum, Department of Neurosciences, University of Helsinki, Room B412b Haartmaninkatu 8, Biomedicum 1, PO Box 700, 00029 HUS Helsinki, Finland

2 HUS Medical Imaging Center, Radiology, University of Helsinki and Helsinki University Hospital, Helsinki, Finland

3 Neurology, Clinical Neurosciences, University of Helsinki and Helsinki University Hospital, Helsinki, Finland best introduced to be tested for consistency, reliability, and for any clinical worth it may have.

\section{Compliance with ethical standards}

Funding Funding information is not applicable.

Conflict of Interest The authors declare that they have no conflict of interest.

Ethical approval This article does not contain any studies with human participants performed by any of the authors.

Informed consent Statement of informed consent was not applicable since the manuscript does not contain any patient data.

\section{References}

1. Johansson E, Fox A (2017) Diagnosing carotid near-occlusion with $1 \mathrm{~mm}$ side-to-side asymmetry: a tough task made too easy. Neuroradiology 59:319-321

2. Koskinen SM, Silvennoinen H, Ijäs P, Nuotio K, Valanne L, Lindsberg PJ, Soinne L (2017) Recognizing subtle near-occlusion in carotid stenosis patients: a computed tomography angiographic study. Neuroradiology 59:353-359 